\title{
LA POESÍA DE ALEXANDRA DOMÍNGUEZ O EL GUSTO DE CELEBRAR*
}

\author{
THE POETRY OF ALEXANDRA DOMÍNGUEZ. \\ THE JOY OF CELEBRATION
}

\author{
María Nieves Alonso \\ Universidad de Concepción. Concepción, Chile \\ malonso@udec.cl
}

La muerte se lleva a los míos, pero sé que volverán.

(Canto religioso)

Los hombres no quieren, no, ver que marchan con fantasmas aunque así van por las rutas $\mathrm{y}$ viven en sus moradas.

(Gabriela Mistral)

\begin{abstract}
MAR, RECOGER, conocer, sonreír; vivir en la negación de la muerte, A abriéndole la puerta al descolorido océano, recordar, no olvidar ni el invierno en que no se estrenó el vestido blanco ni el porvenir del fracaso ni la contradictoria persistencia de la sonrisa del mundo. Sobre todo no olvidar al carpintero que hacía los bastidores donde se desvaneció el miedo a la muerte. Oír y ver escribir. Celebrar esos restos donde prefirió quedarse a vivir la belleza, llevarle flores al padre y no negarse a decir: adelante. Sí, celebrar y agradecer parecen ser los principales motivos de la escritura elegante, fluida y extremadamente preñada de voces de la poeta chilenaespañola Alexandra Domínguez.
\end{abstract}

* Esta nota es resultado de los estudios desarrollados en el proyecto Fondecyt Regular No 1110921, "Poesía chilena del siglo XX: Esbozo de una historia de las relaciones entre poesía y muerte". 
La conquista del aire (XX Premio Hispanoamericano de Poesía Juan Ramón Jiménez 2000) y Poemas para llevar en el bolsillo (XIV Premio de Poesía de Rincón de la Victoria In memoriam Salvador Rueda, 2006) son dos libros que entregan el proyecto poético de quien es asimismo una destacada artista visual. Estos títulos sitúan muy exactamente una obra que se desplaza desde lo ascensional y metafísico a lo que está a flor de tierra que construye la doble genealogía -literaria familiar- del reino de Apolo del de Dyonisios, la del lado de acá, la del lado de allá. Todo aquello que permita a su autora pasar y permanecer eligiendo desatinadamente el aspecto, las acciones que conducen al (re)encuentro, a la recuperación de los instantes del lugar donde habita la belleza y el bien. La palabra conquista aire; llevar, bolsillo sitúan la(s) dirección(es) de esta empresa poética conectadas con el aire que da vida y con la posibilidad de seguir un camino aquí abajo.

Con ecos de esencial experiencia, Domínguez realiza en sus poemas múltiples viajes imaginarios que le permiten la actualización memorística y la instalación física -a través de logos- de lo que constituye o se elige como trayectoria de vida siempre ocurriendo. Los poemas, muchas veces elegías, otras veces crónicas; con títulos sugerentes, privilegian, en todo momento y conscientemente, los recuerdos que sostienen y elaboran una verdadera acción de gracias para todos quienes le han entregado los dones de la belleza y el saber; las pequeñas armas para cumplir su deseo. Mestre, el padre y la madre, en primer lugar, cohabitan con una tribu heterodoxa y potente que va apareciendo y fluyendo con propiedad y delicadeza en esta poesía. Larrea, Kavanagh, Eliot, Wilde, Dublín, Dakar, La tierra baldía, Nerval... ciudades, historias, pintores, pájaros, ríos, libros, versos... Rilke, Chagall, Virginia Woolf, Londres, una ciudad del sur, Keats, Buffalo Bill, Sócrates, Freud, Woody Allen, China, Cervantes, Klee, Violeta Parra, El gran Meaulnes, Dorian Gray, Shakespeare, Camus, Balzac, Dior, Pompidou, El jardín de los cerezos, Verlaine, El Corán, Belfast o Brooklin, la historia de B.B., el padre de Marianne Moore, Ybzni Alahuá, Moby Dick, el Señor Rot, el Cabo Farewell, se dan cita y coexisten en extrema armonía con la loica de pecho rojo, el chirihue amarillo, el zorzal ceniciento, el queltehue de las praderas húmedas, los chincoles de los manzanos silvestres, los terremotos, las casas y los campos usurpados, los cheyennes y los mapuches, el puerco espín y la comadreja, el Misisipi y el Bío-Bío, las Rocosas y los Andes... Todo lo que sirve para soñar con León Felipe, y con otros, que "el poeta es Prometo que 
conserva las palabras olvidadas de la tribu" y para saber que "si estas palabras se pierden... el mundo se tornará en un páramo”.

Poesía para dar gracias, pero también para advertir del peligro, para resistir los mandatos de la nada, para cumplir con el mandato de "recordar el abecedario de nuestra tierra" y no esquivar, como cree la poeta Carmen García, "la cólera / la ceniza de nuestros muertos" (2011: 26).

La república del aire en la que habita la poeta, que también dice escribir con restos: "con estos restos escribo,/ con palabras oídas al amanecer en los bares/. La palabra silencio al lado del aceite dormido,/ la palabra ruido al romperse un cántaro.../. La palabra Jacinto obedece a la primavera.../. La palabra Camino que está llena de gente...” (2000: 25) es una poesía que pasa de la plegaria al homenaje, sin olvidar, la protesta. Esta es la poeta que quisiera escribir un poema en el que un pájaro deshiciera los nudos... escribir para fortificarse en las afueras del festín y del latido, / en el lugar donde el eclipse es resurrección y memoria de un ángel vagabundo” (2006: 35). La Palabra poética alcanza aquí un decidido valor metafísico, sin olvidar los deberes de la ética del otro ni por ello desatender el humor que Domínguez ha aprendido de su maestro Nicanor, de Don Ramón y de otros y que le sirve para conjurar las mistificaciones y el requiebro de las mentiras de uno y otro sesgo. Un ejemplo de este rasgo -la ironía gozosa- está en el poema del Señor Rot, ese saludador profesional, padre de Rit y de Rot (2006: 22). Es que, incluso, en esta obra la palabra aire colocada al lado de la palabra arcoíris tiene los pies en el suelo (2006: 33) y "la muerte no existe/ Existe la caracola que sueña ser pirámide" (2006: 21). Lo referido esboza una diferencia bastante clara con la poesía chilena que he/hemos estudiado, siguiendo la huella de la presencia y visita de la muerte y en la que encontramos momentos poéticos tan extremos como los de Armando Uribe Arce, Marilú Urriola, Carmen García o Enrique Lihn, en los que el cadáver, la muerte, el ataúd, el ahogo y las pérdidas parecen dominarlo todo ${ }^{1}$. Una poesía, la chilena, en la cual Oscar Hahn propone una equivalencia entre leer (escribir) y morir:

\footnotetext{
${ }^{1}$ En nuestro análisis hemos ido percibiendo que la poesía chilena, que pareciera moverse en el ámbito de la finitud, la desesperanza y el descreimiento, deja pequeñas ventanas a lo otro y/o reitera la idea de la poesía como refugio, resistencia, memoria. Así lo hemos concluido, nosotros, en los trabajos ya escritos sobre Schopf, Harris, Urriola, Bello, Pérez, y en nuestra lectura de varios.
} 
Desdichado lector tuya es la mano

Que puso en marcha este reloj de arena

Las sílabas ya caen grano a grano

Allá abajo palpita tu condena

Estas líneas que miras ahora mismo

Son columnas de arena vertical:

Vas con ellas fluyendo hacia el abismo

Vas goteando hacia el fondo del cristal

Ay cómo entre los versos te deslizas

Mira cuán bajo has descendido ya

De peldaño en peldaño viento pisas:

Casi vacío el otro vaso está

Se te acaba la arena no hay demora

Despídete lector: llegó tu hora

("Versos robados", 2008).

La fuerza y presencia de los espectros permiten a Alexandra proponer, por el contrario, una escritura de fantasmales presencias que, en amada circulación, proveen con palabras para conseguir lo que María Zambrano nos ha descrito tan nítidamente al recordarnos que el ser humano, "que es al mismo tiempo algo fallido y solitario, necesita hacerse una realidad entera donde vivir" (1987: 69-70). Y, aunque la obra sea una vivencia de la muerte, es preciso disponer de ella(s) de antemano para poder, precisamente, llegar a ella. Encontrar o proveerse de una pequeña herramienta, diría un filósofo francés, un talismán para volver del otro lado, un albergue, aunque la obra "sea de suyo una vivencia de la muerte, es preciso disponer de antemano de ella para llegar a ese límite" (Faúndez y Vigore del Río, 2013) ${ }^{2}$. Nombrar es entonces conjurar la presencia de vivos y muertos en el territorio de la memoria, refugios que atesoran la huella del otro grabada,

${ }^{2}$ Es el círculo de Blanchot: "Escribir para poder morir. Morir para poder escribir, palabras que nos encierran en su exigencia circular, que nos obligan a partir de lo que queremos encontrar, a no buscar sino el punto de partida y hacer así de ese punto hacia el que sólo nos aproximamos alejándonos, pero que autorizan también esta esperanza: la de asir, la de hacer surgir el término donde ser anuncia lo interminable" (2002: 81). 
en el nombre desnudo. Responsabilidad ante el otro transformada en memoria y no sólo del presente sino también del porvenir. Así, vida y literatura se armonizan en los libros que reviso y en los cuales se deja fluir libre la vida, se hace permanecer en los nombres, en el intercambio simbólico entre muertos y vivos, instalados en el espacio hospitalario de la lengua y en la idea de que la felicidad ${ }^{3}$ ocurre y se encuentra en la memoria. Instalada en la tradición múltiple que brevemente he reseñado, la poesía de Domínguez contribuye además a crear eso que llamamos pueblo y se inscribe en la línea de celebración del verbo descrita por quienes nos han enseñado tanto. Permítaseme citar: "Únicamente donde haya Palabra habrá mundo (...). El ser del hombre se funda en la palabra; más la palabra viene a ser como 'diálogo'. Y este su modo de ser no, es uno de tantos; sólo en cuanto a diálogo la Palabra es esencial al hombre... (...) Una colectividad de hombres irá ascendiendo a la categoría de Pueblo cuando y en la medida en que vaya consiguiendo poblar de leyendas, de historias, de mitos, de poemas, de fantasmas, de apariciones... todo, hasta la tierra -hasta los rascacielos que, por ahora son nuestros por haberlos pagado, no por haberlos vivido en Pueblo" (Heidegger, 2000: 78).

\section{Los rasgos poéticos}

La casa en el aire que construye Alexandra Domínguez está hecha de materiales lingüísticos en los que encontramos las figuras retóricas, los enlaces y desarrollos adecuados para producir el efecto de levedad y espesura que tal espacio requiere. Así, siguiendo a Nicanor Parra, pero variando el esquema, de "El hombre imaginario" encontramos el poema "El poeta es un asunto allí en lo invisible”. La palabra anafórica es reiterada al final de los versos, pero multiplica su presencia en anáforas interiores hasta aparecen incluso tres veces en un solo verso produciendo una intensificación

${ }^{3}$ Faúndez y Vígore del Río (2013) nos recuerdan también estas importantes palabras, que yo había olvidado, de Fernando Savater: "para negarnos a la muerte hay que elegir una empresa, una cruzada, un propósito que se quiera invulnerable y que nos haga deambular por la faz de la Tierra -a nosotros, que nos sabemos mortales, que lo único cierto e inapelable que conocemos es nuestra mortalidad irrevocable- como si fuésemos inaccesibles a la muerte" (Savater, 1986: 255). 
del efecto: “... llama por teléfono/ a chicas invisibles, esperan en esquinas invisibles a otros invisibles" (2000: 9).

La sobredosis del término invisible instala la categoría aérea, en el inicio del poemario del 2000 e indica la necesidad de leer más allá del simple predicado del texto que se autoconfigura como invisible y desacredita la idea de un yo único. Los mismos anaforismos, las múltiples paranomasias de otros poemas como "Mi amigo Eliot tuvo un sueño" junto a la sintaxis de fluidez yuxtapuesta o copulativa/consecutiva, los paralelismos versales, las oposiciones entre mundos y encuentros expresadas en imágenes de la civilización y de la naturaleza densifican, dan espesura, a los alados versos de estos poemas, muchas veces juguetones y rápidos.

La intertextualidad, en la poesía de Domínguez, heterogénea y fundada en la citación de nombres, y asimilación de procesos, más que en la repetición o rememoración de versos, y la (con)fusión entre poeta citado y la poeta que escribe, otorgan a esta obra otras de sus características. Multiplicidad, rapidez y visibilidad son valores estéticos logrados a través de la construcción de oraciones despejadas, de enunciados precisos y sintaxis fundamentalmente lineal, por el desarrollo de enumeraciones simples y complejas y el sutil tono imperativo que presentan algunos poemas. La exactitud y visibilidad de los mismos aparece también en versos que, no obstante, crean cierta sensación de intemporalidad, de un presente hecho de otros presentes casi retratables y que niegan toda o casi toda visión aniquiladora de la muerte ("Vivo en los que viven después de haber respirado su primera mañana,/al lado de los que construyen el recuerdo de su construida aventura... Vivo en la negación de la muerte donde todo pensamiento es un ángel que / huye" (2006: 10)) y la separación de reinos y de seres ("Qué decir de los árboles, qué de su eterna costumbre de quedarse en el / mismo sitio con los pies en el suelo" (2006: 33). El valor de la incertidumbre, la ironía y el humor no están ausentes en estos libros en los que es frecuente encontrar la sencillez de la comparación y la repetición fonológica, semántica y gramatical, y donde se dan razón y exponen sucesos de una formación poética compleja y completa de forma sutil e incluso, delicadamente divertida: "no nos hemos dado cuenta. Lo que pasa/ es que no nos hemos dado cuenta./ Lo único que sabemos con antelación/ es la hora en que va a pasar el cartero,/ los papeles inútiles que dejará en el buzón... yo he comprado en mi vida muchas cosas que significan,/ he comprado agua 
de borrar manos, / he comprado un libro de poemas, una aguja, hilo/ Mi vida está hecha de cosas significantes amigas de la felicidad... Mi vida es pensar un largo rato,/ la escalera apoyada en un rincón de la vieja, las herramientas del jardinero" (2000: 23-24).

Con toda su tribu de seres, con el rumor de palabras oídas y leídas, con el recuerdo de ciertas cosas hechas, con sentimientos amorosos aun en la denuncia, la poeta escribe esta poesía de lo cotidiano y exploratoria de otras formas de lo real y en la que la belleza es un pasaporte valiente y audaz para vivir: "He amado los préstamos, esa pequeña felicidad que va quedando en las/ fotos/ Los he visto entrar sin futuro donde es nadie el alcohol y nadie también el cerezo./ He recogido con manos furtivas sus frutos en lugares furtivos/ nada más verdadero que el ala de un ángel sobre la columna... He amado a Fitzgerald y a Wisky, he amado a Mestre..." (2006: 8). Los préstamos, los traspasos, los cruces, el amoroso distinguir, nombrar y hacer presente, se evidencian también en la recreación de paisajes afectivos y la sistemática zoología y botánica que circula en estos poemas. La presencia de estos seres, prácticamente todos tiernos, frágiles o familiares, acentúan las nociones de levedad y movilidad tan entrañable de esta escritura que asimismo desarrolla el encabalgamiento y la metonimia, pues "todo recuerdo tiene siete brazos como el calendario hebreo sobre la mesa de pino", hay algunas cosas para no olvidar y, por poner un ejemplo, "sin duda, Gonzalo Rojas debería figurar en la Antología de Spoon/River./ De alguna manera Edgar Lee Masters le dejó un sitio entre Robert Davidson y Elsa Wertman" (2006: 16). Esta es una poesía a cuya protagonista le gusta el "grillo que canta en la estantería junto al hombre que fue jueves", "los estuches de violín donde duermen las manos dóciles” y ama los pasillos de la memoria por los que regresa a su casa y allí está su "padre distraído por la iluminación definitiva de los pensamientos" (2006: 47) y escribe para los insectos (2006: 19). Barquito que unos pierden y otros encuentran, entrar y salir del propio territorio, volver con otros bienes, anudar y desanudar ha sido el trabajo de muchos artistas en los últimos años. Vivir para recrear, poner a prueba la significación de la obra en un mundo (casi) huérfano de paradigmas, armar fugas, infiltrar, robar, mostrar el contrabando y mostrarse, parecen modos con los que Alexandra construye sus poemas.

$\mathrm{La}(\mathrm{s})$ palabras(s) de la poeta de Concepción se instala(n) en su tradición, surgen de su memoria y corazón para así contribuir a formar aquello 
que se llama pueblo, pues su colectividad de seres irá ascendiendo a esta categoría "cuando y en la medida en que vaya consiguiendo poblar de leyendas, de historias, de mitos, de poemas, de fantasmas, de apariciones" un territorio (Heidegger, 2000: 78) y permita habitar la casa del lenguaje, recorrer sus múltiples moradas y tomar, acrecentar, la propia con los dones de los antepasados y los prójimos.

\section{Casa - República - Poesía}

La poeta de esta historia necesita -ha necesitado- de la intervención de más de un fantasma para aprender a vivir en la sociedad que se niega a admitir el valor de agradecer, el valor de la belleza y la importancia de lo pequeño, la existencia de gente diferente. Conoce esa "política de la memoria" que exigen sus muertos y los de los otros; sabe, muy bien, que para construir una casa o una república se necesita de la intervención de aquéllos, pues lo que sucede entre dos, entre todos los dos que se quiera, como entre vida y muerte, siempre precisa para mantenerse de algún fantasma. (Vivir) de otra manera. Y mejor. No mejor: más justamente. Pero con ellos. No hay "ser con" el otro, no hay "socius" sin este "con-ahí" que hace el "ser-con" en general más enigmático que nunca. Y ese ser-con los espectros sería también, no sólo, pero sí también, una política de la memoria, de la herencia y de las generaciones (Derrida, 1958: 12). Hay espíritus y hay que contar con ellos, hablar de ellos, hablarles para construir nuestra propia participación en la casa de todos, esa República ideal o ideada en la que el lado de acá y el de allá se encuentran.

Así, la protagonista, la habitante de la poesía que comento, vive "en la casa de los peces donde el hombre es un río lejano", vive "entre los que permanecen inmóviles esperando la resurrección de su/ nada", "en los que desaparecieron", "al lado de los que construyen el recuerdo de su concluida aventura", "en la negación de la muerte" (2006: 10).

También va a la casa de los locos cada mañana, atesora una casa con cerezos, el lugar donde, a los doce años, oye a su padre hablar de El extranjero. El zumbido es el mismo, multiplicándose en otros. Es el murmullo de la infancia que no pasa, que está siempre en el discurso, protegiendo del desencanto y del terror. Es matriz del discurso de una poeta que necesita, 
dice, creer en tres cosas, en tres metonimias de lo sagrado: "ojos extranjeros en la octava región de la provincia tristeza", la poeta tiene "paciencia para recordar y paciencia para dibujar un círculo/ oscuro,/ dentro de él está Schiller; hermano de los bisontes...”, asimismo escribe: “yo necesito creer en estas tres cosas: en esta violeta, en la gratitud, en mi padre" (2006: $50,48,39)$. También declara que "La gratitud es la tierra a la que han vuelto para compartir los espejos de agua/ la guitarra y el código./ Mi padre dejó discípulos en la gratitud de algunas palabras que describen la verdad y la justicia./ La muchacha se llama Violeta Parra, como el rocío de la gran Cordillera y los cisnes negros del Sur que anidan en la maravilla...” (2006: 38).

Celebración del pasado que no pasa y celebración de la espera. La espera, que con el término esperanza son inseparables de la palabra utopía, existe en la poesía de Alexandra junto a un gran despliegue de experiencias particulares poetizadas con una notable competencia estética y gran valor ético. En las personales y propias recupero el otro tiempo y, muy especialmente, la presencia del padre, figura central del texto, anudado copulativamente a una gran tribu de seres y saberes con los que construir la casa en el aire, la república en la que no haya desaparecidos, ni Antígona alguna que deba buscarlos. Una república en la que caminemos con los bolsillos llenos de poemas: $\mathrm{y}+\mathrm{y}+\mathrm{y}+\mathrm{y}+\mathrm{y}+\ldots$ Es esta una poesía hospitalaria en la que Domínguez recupera para nosotros palabras de la tribu desechadas torpemente y que llena de aire la poesía chilena, al tiempo que nos invita a pasar para celebrar y compartir el escándalo de la revelación, según la cual, de una parte el otro está muerto, de la otra es indestructible”. Todo en un espacio: en que el murmullo, la voz de los espectros y los de los vivos son voces que se unen en voces acordadas... pasad palabras olvidadas o envanecidas: comunicar, celebrar, consagrar, agradecer, alabar, loar, amar, pasad cerezas, lluvia, entrad seres inexistentes cuya única virtud fue ser una alacena sin alimentos para la melancolía o el odio, maderas flotando después del naufragio; ven Ramón Riquelme que es como Dostoiewski, Zweig, Sócrates y Pitágoras a la vez; las palabras nieve, arco o mariposa pero con los pies en el suelo. Adelante "Pasad viento y lluvia a este rincón del jardín donde las Bronté hacen/ ganchillo" (2006: 32).

Concluyo con una cita de Bajtín que dice mucho mejor de lo que yo pudiera nunca, uno de los valores de la poesía de Domínguez: 
La naturaleza dialógica de la conciencia, la naturaleza de la vida humana. La única forma adecuada de la expresión verbal de una auténtica vida humana es el diálogo inconcluso. La vida es dialógica por su naturaleza. Vivir quiere decir participar en un diálogo: preguntar, poner atención, responder, estar de acuerdo. En este diálogo, el nombre completo toma parte con toda su vida: con sus ojos, labios, manos, alma espíritu, el cuerpo entero, los actos. Su ser entero se le va en la palabra, que se introduce en el tejido dialógico de la vida de los seres humanos, en el simposio universal (Bajtín, 1985: 165).

\section{Referencias}

Bajtín, M. (1985). Estética de la creación verbal. México: Siglo Veintiuno Editores.

Blanchot, M. (2002). El espacio literario. Madrid: Alianza Editorial.

Derrida, J. (1958). Políticas de la amistad. Madrid: Trotta. (1995). Espectros de Marx. Valladolid: Editorial Trotta.

Domínguez, A. (2000). La conquista del aire. Huelva: Colección Juan Ramón Jímenez.

. (2006). Poemas para llevar en el bolsillo. Rincón de la Victoria, Málaga: Editorial Renacimiento.

Faúndez, E. y Vígore del Río, A. (2013). ¿Cómo decirle que no? La poesía de Floridor Pérez. Inédito.

García, C. (2011). Gotas sobre loza fría. Santiago: Cuarto Propio.

Hahn, O. (2008). Antología virtual. México D.F.: Fondo de Cultura Económica.

Heidegger, M. (2000). Hölderlin y la esencia de la poesía. Barcelona: Anthropos.

Savater, F. (1986). El contenido de la felicidad. Madrid: Ediciones El País.

Zambrano, M. (1987). Hacia un saber sobre el alma. Madrid: Alianza. 